\title{
Application of Carboxymethyl Chitosan-Benzaldehyde as Anticorrosion Agent on Steel
}

\author{
Handoko Darmokoesoemo $\mathbb{D}^{1},{ }^{1}$ Suyanto Suyanto, ${ }^{1}$ Leo Satya Anggara, ${ }^{1}$ \\ Andrew Nosakhare Amenaghawon, ${ }^{2}$ and Heri Septya Kusuma $\mathbb{1}^{3}$ \\ ${ }^{1}$ Department of Chemistry, Faculty of Science and Technology, Airlangga University, Surabaya 60115, Indonesia \\ ${ }^{2}$ Department of Chemical Engineering, Faculty of Engineering, University of Benin, PMB 1154, Ugbowo, Benin City, Edo State, Nigeria \\ ${ }^{3}$ Department of Chemical Engineering, Faculty of Industrial Technology, Institut Teknologi Sepuluh Nopember, \\ Surabaya 60111, Indonesia
}

Correspondence should be addressed to Handoko Darmokoesoemo; handoko.darmokoesoemo@gmail.com and Heri Septya Kusuma; heriseptyakusuma@gmail.com

Received 26 August 2017; Revised 9 December 2017; Accepted 20 December 2017; Published 16 April 2018

Academic Editor: Sébastien Déon

Copyright (C) 2018 Handoko Darmokoesoemo et al. This is an open access article distributed under the Creative Commons Attribution License, which permits unrestricted use, distribution, and reproduction in any medium, provided the original work is properly cited.

\begin{abstract}
Corrosion is one of the problems that is often found in daily life especially in petroleum and gas industry. Carboxymethyl chitosan(CMC-) benzaldehyde was synthesized as corrosion inhibitor for steel. Corrosion rate was determined by potentiostatic polarization method in $\mathrm{HCl} 1 \mathrm{M}$. Dripping and coating, two different treatment, were used to drop and coat steel by CMC-benzaldehyde. The results showed that CMC-benzaldehyde could inhibit the corrosion rate of steel with concentration of $1 \mathrm{~g}, 3 \mathrm{~g}, 5 \mathrm{~g}$, and $7 \mathrm{~g}$ in $60 \mathrm{~mL}$ of solvent. Coating steel with CMC-benzaldehyde with concentration of $7 \mathrm{~g} / 60 \mathrm{~mL}$ of solvent and starch of $0.1 \mathrm{~g} / \mathrm{mL}$ showed the highest efficiency to inhibit corrosion rate of steel. These treatments give corrosion efficiency of $99.8 \%$.
\end{abstract}

\section{Introduction}

Corrosion is one of the most common problems found in everyday life, especially in the oil and gas processing industry. Corrosion cannot be prevented or stopped but its rate of destruction can be controlled. Corrosion is the degradation (destruction or degradation of quality) of metal properties through electrochemical reactions that are natural and take place by themselves due to chemical phenomena with the environment. The factors that cause corrosion include air pollution levels, temperature, humidity, and the presence of chemicals that are corrosive [1].

Corrosion-induced impacts can be direct and indirect impacts. Direct impacts include damage to equipment, machinery, and building structures. Indirect impacts result from cessation of production activities due to the replacement of equipment damaged by corrosion. Indirect costs incurred are generally larger than direct costs [2]. Therefore, various attempts are made to inhibit corrosion.
In the oil drilling and processing industry, corrosion becomes an inseparable problem. Uncontrolled corrosion rate can result in a malfunction of the equipment used, especially on offshore oil drilling platforms with high saline environments.

Corrosion that occurs in the metal causes a loss that is not small financially. The economic factor becomes a very important motivation for many current studies to be able to overcome and inhibit the rate of corrosion. According to a recent study, the losses suffered by industry and government in the United States amount to approximately 276 billion US dollar or about 3.1 percent of Gross Domestic Product (GDP). Studies on corrosion in Australia, England, Japan, and other countries have also been conducted. Nearly every country spends about 3-4 percent of Gross Domestic Product (GDP) to overcome corrosion. Total losses due to corrosion can be avoided around 25-30 percent if corrosion prevention can be done effectively [3]. 
There are various efforts of metal protection to overcome corrosion, among others; surface coating and cathode protection systems require a high cost because of the selection of inhibitors used. The effort has also not been effective in overcoming corrosion. In this research, corrosion inhibitor from organic material as anticorrosion is used. This inhibitor is chosen because it has a high affinity on the metal with high efficiency and being friendly to the environment. The corrosion inhibitor used is, namely, carboxymethyl chitosan (CMC) which is substituted with benzaldehyde.

Carboxymethyl chitosan (CMC) is a derivative of chitosan derived from chitin isolated from terrestrial invertebrates, marine invertebrates, and fungi which are numerous in nature. In invertebrates, chitin serves as an exoskeleton composite matrix, whereas in fungi it functions as a cell wall shaper. Chitosan is a soluble solid in acetic acid and easily degraded, but the application of chitosan is limited because it is not water soluble [4].

The use of CMC in this study is preferred over chitosan itself. This is because CMC has an important characteristic that is water soluble, high gel forming capacity, low toxicity, and good biocompatibility so that the application will be wider [5]. In addition, CMC is widely used because it is amphiprotic, which contains the $-\mathrm{COOH}$ and $-\mathrm{NH}_{2}$ groups in its molecules that have many free electron pairs.

In this study, the $-\mathrm{NH}_{2}$ group present in CMC (acting as base) is substituted with benzaldehyde to form carboxymethyl chitosan-benzaldehyde (CMC-benzaldehyde) compound. These compounds are expected to be used as an effective and effective anticorrosion in inhibiting the corrosion rate on steel. CMC-benzaldehyde is used as a corrosion inhibitor due to the presence of heteroatoms $(\mathrm{O}$ and $\mathrm{N})$, the phi bond formed between CMC and benzaldehyde, and the number of free electrons that can support the inhibitor in chemisorption with the metal by coordination [6].

Therefore, in this study the inhibition of corrosion rate was carried out on the steel in the medium of $\mathrm{HCl} 1 \mathrm{M}$ using the CMC-benzaldehyde inhibitor. The method used to determine the corrosion rate is the measurement of the intensity of corrosion current on steel with potentiostatic polarization.

\section{Materials and Methods}

2.1. Materials and Tools. The materials used in this study were chitosan from Good Manufacturing Practice, glacial acetic acid, $\mathrm{NaOH}$, chloroacetic acid, isopropanol, ethanol $99.8 \%$, distilled water, double-distilled water, benzaldehyde, commercial steel, filter paper, cassava, and $\mathrm{HCl} 37 \%$, while the tool used in this research is Fourier Transform Infrared Spectrometer (FTIR) SHIMADZU, Potentiostat PGSTAT302N corrosion test instrument coupled with computer and Autolab NOVA software and SEM-EDX Carl Zeiss EVO MA 10.

\subsection{Synthesis of CMC and CMC-Benzaldehyde}

2.2.1. Synthesis of CMC. A total of $10 \mathrm{~g}$ of chitosan was dissolved in $400 \mathrm{~mL}$ of acetic acid $2 \%$. The soluble chitosan was added to $13.5 \mathrm{~g}$ of $\mathrm{NaOH}$ and was reacted over the water bath at $50^{\circ} \mathrm{C}$ for 1 hour. The solution was refluxed and added to $15 \mathrm{~g}$ of chloroacetic acid which has been dissolved in $20 \mathrm{~mL}$ of isopropanol. The mixture was reacted for 4 hours at $50^{\circ} \mathrm{C}$. The treated mixture was filtered off with a Buchner funnel and washed with ethanol $70 \%$. The obtained precipitate is dried at room temperature. The result is a CMC which is then characterized using FTIR [8].

2.2.2. Synthesis of CMC-Benzaldehyde. A total of $20 \mathrm{~g}$ of $\mathrm{CMC}$ was dissolved in $400 \mathrm{~mL}$ of distilled water. The solution was reacted with benzaldehyde-ethanol with a ratio of $1: 1$ ( $5 \mathrm{~mL}$ of benzaldehyde mixed with $5 \mathrm{~mL}$ of ethanol). The temperature used during the reaction takes approximately $50-60^{\circ} \mathrm{C}$. The reaction was carried out for 5 hours and then filtrate and the precipitate was filtered using a Buchner funnel and washed with ethanol $70 \%$. The precipitate obtained is the result of the synthesis of CMC-benzaldehyde. CMCbenzaldehyde obtained was characterized using FTIR [9].

2.3. Preparation of Starch. A total of $1 \mathrm{~kg}$ of cassava is cleaned and peeled. Then the cassava is smoothed using a grinder. Finely ground cassava is then soaked in distilled water for 24 hours. The filtrate and the precipitate are separated by decantation. The precipitate obtained is dried to obtain a starch made from cassava. A total of $5 \mathrm{~g}$ of starch was dissolved in $50 \mathrm{~mL}$ of hot aquades by stirring until a homogeneous solution was obtained. This formed starch solution is mixed in CMC-benzaldehyde.

2.4. Treatment for Steel. The steel used in this study was cleaned by sand and cut with length of $20 \mathrm{~mm}$, width of $10 \mathrm{~mm}$, and thick of $1 \mathrm{~mm}$. The chemical composition content of the steel was tested using EDX (Energy Dispersive X-Ray) analysis.

\subsection{Testing of Corrosion Rate on Steel in $\mathrm{HCl} 1 \mathrm{M}$}

2.5.1. Testing of Corrosion Rate on Steel without Addition of CMC-Benzaldehyde. The steel is first immersed in $100 \mathrm{~mL}$ of $\mathrm{HCl} 1 \mathrm{M}$ for 120 hours. After the corrosion process runs during that time, the steel is taken and washed with doubledistilled water. Furthermore, the steel is left for a while and then heated in an oven at a temperature of $45-50^{\circ} \mathrm{C}$ for 10 minutes. Testing of corrosion rates on steels in $\mathrm{HCl} 1 \mathrm{M}$ without addition of CMC-benzaldehyde was performed by potentiostatic polarization method as shown in Figure 1.

\subsubsection{Testing of Corrosion Rate on Steel with the Addition} of CMC-Benzaldehyde. Tests of corrosion rates on steels in $\mathrm{HCl} 1 \mathrm{M}$ were carried out with two treatments, dripping and coating, wherein each treatment was added to CMCbenzaldehyde without starch and with starch. Dripping with the addition of CMC-benzaldehyde was performed by dissolving CMC-benzaldehyde of $1 \mathrm{~g}, 3 \mathrm{~g}, 5 \mathrm{~g}$, and $7 \mathrm{~g}$ in a mixture of $20 \mathrm{~mL}$ of distilled water, $20 \mathrm{~mL}$ of acetic acid $2 \%$, and $20 \mathrm{~mL}$ of alcohol at a ratio of $1: 1: 1$. Subsequently a $100 \mathrm{~mL}$ of $\mathrm{HCl} 1 \mathrm{M}$ was added to the solution of CMCbenzaldehyde by stirring until homogeneous. The solution is 


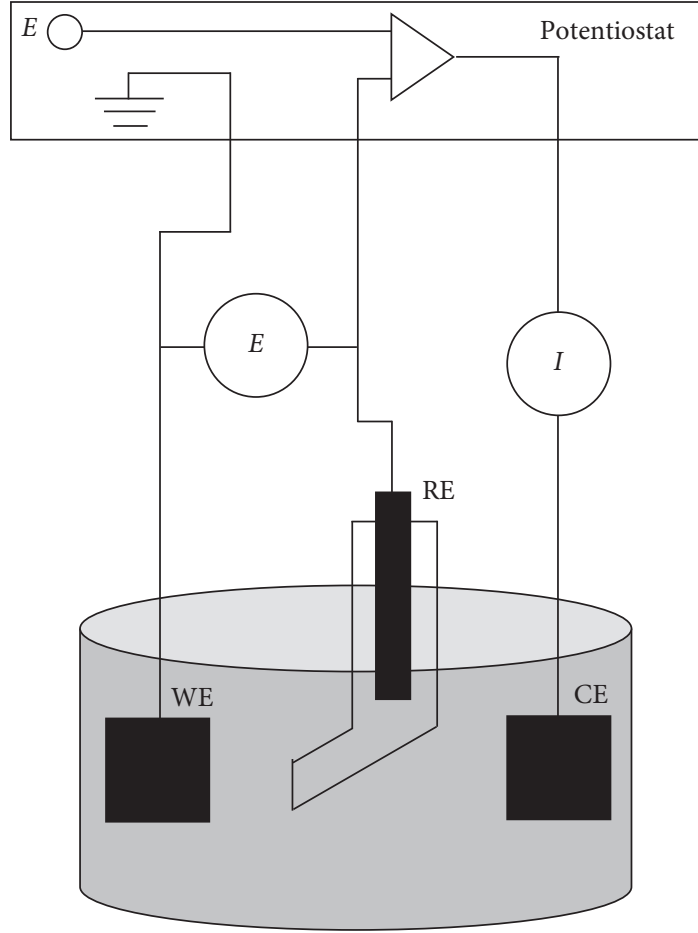

FIGURE 1: The series of equipment for potentiostatic polarization method (working electrode is carbon steel, reference electrode is $\mathrm{Hg}_{2} \mathrm{Cl}_{2}$, and counter electrode is platinum).

closed and left for 72 hours. Next, the steel is immersed in the solution for 120 hours.

Dripping with the addition of CMC-benzaldehyde using starch was performed by dissolving CMC-benzaldehyde of $1 \mathrm{~g}, 3 \mathrm{~g}, 5 \mathrm{~g}$, and $7 \mathrm{~g}$ in a mixture of $20 \mathrm{~mL}$ of distilled water, $20 \mathrm{~mL}$ of acetic acid $2 \%$, and $20 \mathrm{~mL}$ of alcohol at a ratio of $1: 1: 1$. Furthermore, the solution of CMC-benzaldehyde was added to starch solution of $1 \mathrm{~mL}, 3 \mathrm{~mL}, 5 \mathrm{~mL}$, and $7 \mathrm{~mL}$ with a concentration of $0.1 \mathrm{~g} / \mathrm{mL}$ and $100 \mathrm{~mL}$ of $\mathrm{HCl} 1 \mathrm{M}$. The solution is closed and left for 72 hours. Next, the steel is immersed in the solution for 120 hours.

Coating with the addition of CMC-benzaldehyde was performed by dissolving CMC-benzaldehyde of $1 \mathrm{~g}, 3 \mathrm{~g}, 5 \mathrm{~g}$, and $7 \mathrm{~g}$ into a mixture of $20 \mathrm{~mL}$ of aquades, $20 \mathrm{~mL}$ of acetic acid $2 \%$, and $20 \mathrm{~mL}$ of alcohol at a ratio of $1: 1: 1$ The steel is then immersed in the solution for 72 hours. After a predetermined time, the steel is taken and put into the oven so that CMC-benzaldehyde can adhere to the steel. Furthermore, the steel is immersed in $100 \mathrm{~mL}$ of $\mathrm{HCl} 1 \mathrm{M}$ for 120 hours.

Coating with the addition of CMC-benzaldehyde using starch was carried out by dissolving CMC-benzaldehyde of $1 \mathrm{~g}, 3 \mathrm{~g}, 5 \mathrm{~g}$, and $7 \mathrm{~g}$ in $20 \mathrm{~mL}$ of aquades, $20 \mathrm{~mL}$ of acetic acid $2 \%$, and $20 \mathrm{~mL}$ of alcohol at a ratio of $1: 1: 1$. Each solution was added to starch solution of $1 \mathrm{~mL}, 3 \mathrm{~mL}, 5 \mathrm{~mL}$, and $7 \mathrm{~mL}$ with a concentration of $0.1 \mathrm{~g} / \mathrm{mL}$. Furthermore, steel is immersed in the solution for 72 hours. After a predetermined time, the steel is taken and put into oven so that CMC-benzaldehyde and starch can adhere to the steel. Furthermore, the steel is immersed in $100 \mathrm{~mL}$ of $\mathrm{HCl} 1 \mathrm{M}$ for 120 hours.

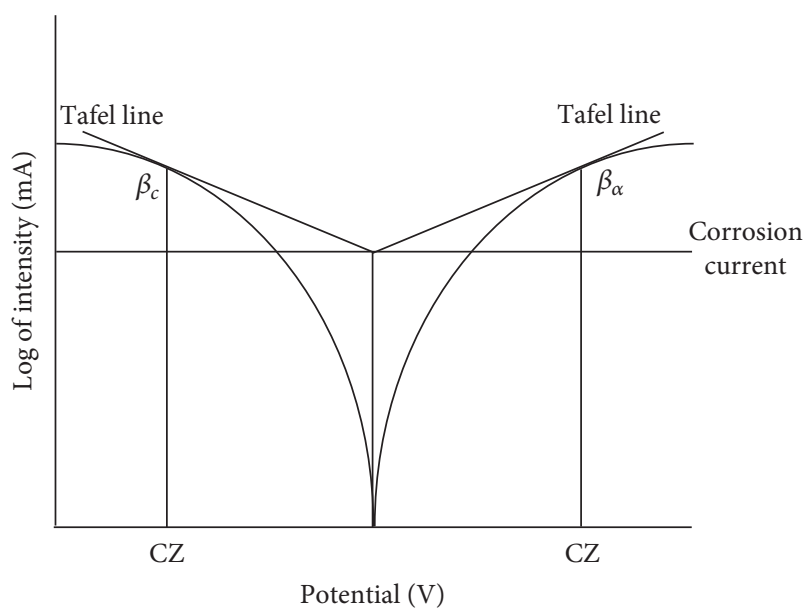

FIGURE 2: The curve between potential against log of current intensity.

After the corrosion process takes place with the dripping and coating treatment during that time, the steel is removed and washed with double-distilled water. Furthermore, the steel is left for a while and then heated in an oven at a temperature of $45-50^{\circ} \mathrm{C}$ for 10 minutes. The corrosion rate test on steel in $\mathrm{HCl} 1 \mathrm{M}$ with the addition of CMCbenzaldehyde was performed by potentiostatic polarization method as shown in Figure 1.

2.6. Determination of Corrosion Rate. In this study, the determination of corrosion rate was done by determining the intensity of corrosion current with potentiostatic polarization using the correlation between potential with log of current intensity to obtain intensity of corrosion current $\left(I_{\text {corr }}\right)$ and corrosion rate $\left(v_{\text {corr }}\right)$ as shown in Figure 2. The relationship between the intensity of corrosion current $\left(I_{\text {corr }}\right)$ and corrosion rate $\left(v_{\text {corr }}\right)$ is illustrated by the following equation:

$$
v_{\text {corr }}=\frac{0.13 \times I_{\text {corr }} \times \mathrm{EW}}{\rho},
$$

where $v_{\text {corr }}$ is the rate of corrosion (mpy), $I_{\text {corr }}$ is the intensity of corrosion current $\left(\mu \mathrm{A} / \mathrm{cm}^{2}\right)$, EW is the equivalent weight (atomic weight/valence) (g), and $\rho$ is the density $\left(\mathrm{g} / \mathrm{cm}^{2}\right)$.

The smaller corrosion rate of a material indicates the greater resistance of the inhibitor in inhibiting corrosion. Conversely, the greater corrosion rate of a material indicates the smaller resistance of the inhibitor in inhibiting corrosion. The intensity value of corrosion current $\left(I_{\text {corr }}\right)$ is obtained by performing Tafel analysis with semimanual way by extrapolating the linear part of a plot log of the current intensity with potential at the current meeting of the anode and cathode.

The determination of potential calculation zone (CZ) of the anode and cathode curves affects the slope of cathode curve $\left(\beta_{c}\right)$ and the slope of anode curve $\left(\beta_{\alpha}\right)$ which directly 


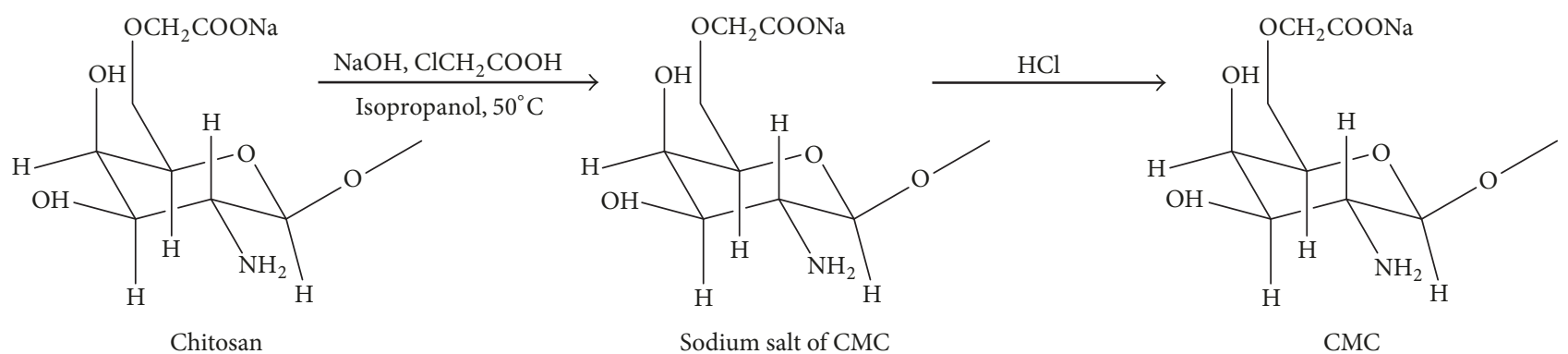

FIgURE 3: Synthesis of CMC from chitosan.

determines the intensity value of corrosion current $\left(I_{\text {corr }}\right)$. This is shown by the Stern-Geary equation as follows:

$$
I_{\text {corr }}=\frac{\beta_{c} \times \beta_{\alpha}}{2.3 \times\left(\beta_{c}+\beta_{\alpha}\right) \times A \times R_{p}},
$$

where $I_{\text {corr }}$ is the intensity of the corrosion current $\left(\mu \mathrm{A} / \mathrm{cm}^{2}\right)$, $\beta_{c}$ is the slope of cathode curve, $\beta_{\alpha}$ is the slope of anode curve, $A$ is the area $\left(\mathrm{cm}^{2}\right)$, and $R_{p}$ is the polarization resistance $\left(\mathrm{k} \Omega / \mathrm{cm}^{2}\right)$. The slope value of the cathode and anode curves for each element or type of metal is not necessarily same, depending on the corresponding valence in the corrosion reaction that occurs.

2.7. Testing Morphology on Steel. The morphological test on steel aims to find out the steel surface structure as a result of the addition of inhibitors to corrosive media [10]. For morphological testing of steel samples, the steel samples are placed on top of the preparations and then observed by Scanning Electron Microscope (SEM) so that the surface structure and corrosion type on the steel can be seen clearly as a result of the addition of CMC-benzaldehyde.

2.8. Data Analysis. Data obtained from test results in the form of current and potential using potentiostat PGSTAT302N were processed by Tafel analysis with semimanual way to obtain the intensity of corrosion current $\left(I_{\text {corr }}\right)$ and corrosion rate $\left(v_{\text {corr }}\right)$. The Tafel analysis is performed by extrapolating the linear part of a plot log of the current intensity with the potential at the current meeting of the anode and cathode. From the intersection of the line, the intensity of corrosion current $\left(I_{\text {corr }}\right)$ is obtained that can be converted to obtain the rate of corrosion $\left(v_{\text {corr }}\right)$ in accordance with (1). In this research, potentiostat PGSTAT302N with Autolab NOVA software is used so that the corrosion rate $\left(v_{\text {corr }}\right)$ can be obtained together with the intensity of corrosion current $\left(I_{\text {corr }}\right)$ at the time of Tafel analysis from the relationship between the curve of the potential and the log of current intensity. Data analysis of the effect of variation concentration of CMC-benzaldehyde on the inhibition of corrosion rate on steel is shown in the form of graph and table.

2.9. Inhibition Efficiency of CMC-Benzaldehyde against Corrosion Rate. Inhibitor efficiency is an inhibitor's ability to inhibit corrosion rate efficiently when compared to without using inhibitors. To determine the efficiency of inhibitor in reducing and controlling corrosion rate on carbon steel, in this study the efficiency of inhibitor is calculated using the following equation:

$$
\text { Inhibition efficiency }(\%)=\frac{V_{k 0}-V_{k 1}}{V_{k 0}} \times 100 \% \text {, }
$$

where $V_{k 0}$ is the corrosion rate without using inhibitor and $V_{k 1}$ is the corrosion rate using inhibitor.

\section{Results and Discussion}

3.1. Synthesis of CMC-Benzaldehyde. The synthesis of CMCbenzaldehyde is done by reacting CMC with benzaldehyde. In the formation of CMC-benzaldehyde, CMC need to be synthesized by reacting chitosan with $\mathrm{NaOH}$ and chloroacetic acid as shown in Figure 3 [7]. CMC formed can dissolve completely in water.

The formation of CMC-benzaldehyde occurs through the reaction mechanism of the formation of an imine. The stage of imine formation which essentially occurs in two stages is addition and elimination. The first stage is the addition of the nucleophilic amine to carbonyl carbon which has a partial positive charge followed by the release of protons from nitrogen and the acquisition of protons in oxygen. The second stage is the protonation of the $\mathrm{OH}$ group which can be released as water in an elimination reaction. The reaction mechanism of CMC-benzaldehyde formation is shown in Figure 4 .

3.2. Characterization of Chitosan, CMC, and CMC-Benzaldehyde Using Fourier Transform Infrared Spectrometer (FTIR). Characterization using Fourier Transform Infrared Spectrometer (FTIR) is used to determine the functional group of a compound formed on a particular wave number. The FTIR spectrum of chitosan and CMC according to Zheng et al. [7] is shown in Table 1.

The FTIR spectrum of chitosan used for the synthesis of CMC can be seen in Figure 5. The FTIR spectrum of chitosan shows the following wave numbers: $1033.77-1083.92 \mathrm{~cm}^{-1}(\mathrm{C}-$ O stretch), $1153.35 \mathrm{~cm}^{-1}$ (bridge-O stretch), $1421.44 \mathrm{~cm}^{-1}(\mathrm{~N}-$ $\mathrm{H}$ bending), $2883.38 \mathrm{~cm}^{-1}$ (C-H stretch), and $3440.77 \mathrm{~cm}^{-1}$ (O-H stretch).

The FTIR spectrum of CMC can be seen in Figure 6. The FTIR spectrum of CMC from the synthesis results 

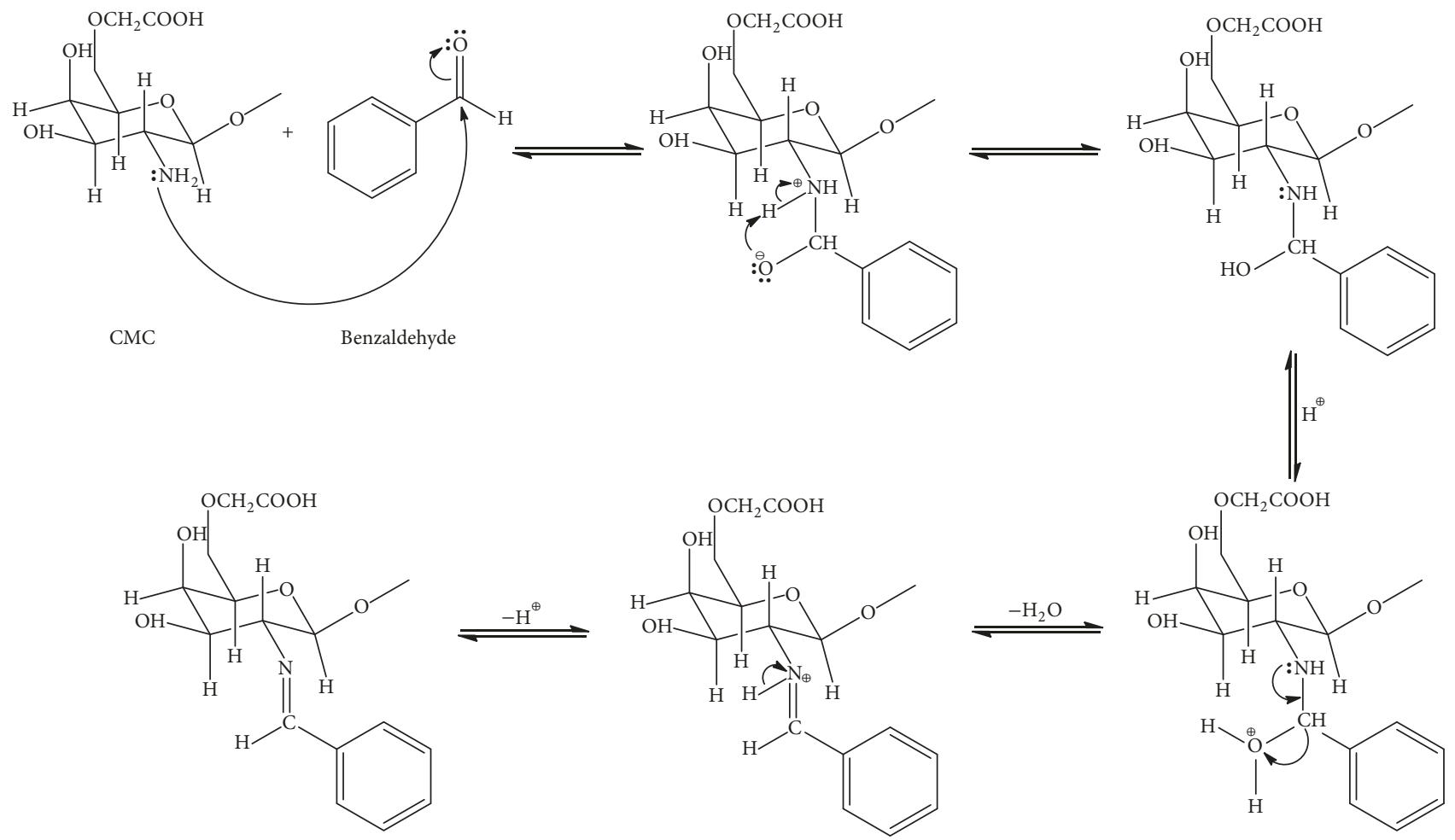

CMC-benzaldehyde

FIGURE 4: Reaction mechanism of CMC-benzaldehyde formation.

TABLE 1: Analysis of functional groups of chitosan and CMC using FTIR.

\begin{tabular}{lccc}
\hline Functional groups & $\begin{array}{c}\text { Wave numbers according to } \\
\text { Zheng et al. [7] }\left(\mathrm{cm}^{-1}\right)\end{array}$ & $\begin{array}{c}\text { Wave numbers of chitosan } \\
\left(\mathrm{cm}^{-1}\right)\end{array}$ & $\begin{array}{c}\text { Wave numbers of CMC } \\
\text { from the synthesis results } \\
\left(\mathrm{cm}^{-1}\right)\end{array}$ \\
\hline C-O stretch & $1030-1094$ & $1033.77-1083.92$ & $1033.77-1081.99$ \\
Bridge-O stretch & 1153 & 1153.35 & 1151.42 \\
N-H bending & 1556 & 1421.44 & 1598.88 \\
C-H stretch & 2881 & 2883.38 & 2889.17 \\
O-H stretch & 3421 & 3440.77 & 3434.98 \\
COO $^{-}$ & $1407-1598$ & - & 1407.94 \\
\hline
\end{tabular}

shows the following wave numbers: $1033.77-1081.99 \mathrm{~cm}^{-1}(\mathrm{C}-$ O stretch), $1151.42 \mathrm{~cm}^{-1}$ (bridge-O stretch), $1598.88 \mathrm{~cm}^{-1}(\mathrm{~N}-$ $\mathrm{H}$ bending), $2889.17 \mathrm{~cm}^{-1}$ (C-H stretch), $3434.98 \mathrm{~cm}^{-1}(\mathrm{O}-\mathrm{H}$ stretch), and $1407.94 \mathrm{~cm}^{-1}\left(\mathrm{COO}^{-}\right)$, while the wave number of $1407.94 \mathrm{~cm}^{-1}$ shows the existence of a new group formed from the esterification reaction of chitosan into $\mathrm{CMC}$, that is, $\mathrm{COO}^{-}$.

The functional groups formed on chitosan and CMC can be seen in Table 1 . The FTIR spectrum of CMC from the synthesis results obtained in this study showed similar results with the FTIR spectrum of CMC according to Zheng et al. [7].

The formation of CMC-benzaldehyde is demonstrated by the presence of new functional group, the imines $(C=N)$ and $\mathrm{C}=\mathrm{C}$ aromatic, which can be seen at the wave numbers for those groups in the FT-IR spectrum shown in Figure 6. According to Pretsch et al. [11], the wave number for imine $(\mathrm{C}=\mathrm{N})$ is $1645 \mathrm{~cm}^{-1}$ and for $\mathrm{C}=\mathrm{C}$ aromatic is $1600 \mathrm{~cm}^{-1}$. The wave number of CMC-benzaldehyde from the synthesis results is $1641.31 \mathrm{~cm}^{-1}$ for imines $(\mathrm{C}=\mathrm{N})$ and $1450-1600.81 \mathrm{~cm}^{-1}$ for $\mathrm{C}=\mathrm{C}$ aromatic as shown in Table 2 . So based on the characterization using FTIR, it can be said that CMC-benzaldehyde from the synthesis results has formed new functional group which is imine $(\mathrm{C}=\mathrm{N})$ and $\mathrm{C}=\mathrm{C}$ aromatic. The shift of wave numbers in the FTIR spectrum of chitosan, CMC, and CMC-benzaldehyde in this study is shown in Figure 7.

3.3. Mechanism of Corrosion. Corrosion in the metal is an irreversible oxidation-reduction reaction occurring between the metal and the oxidizing agent in an environment. There are various chemicals in the environment that can accelerate the occurrence of corrosion such as acidic, salt, and alkaline 


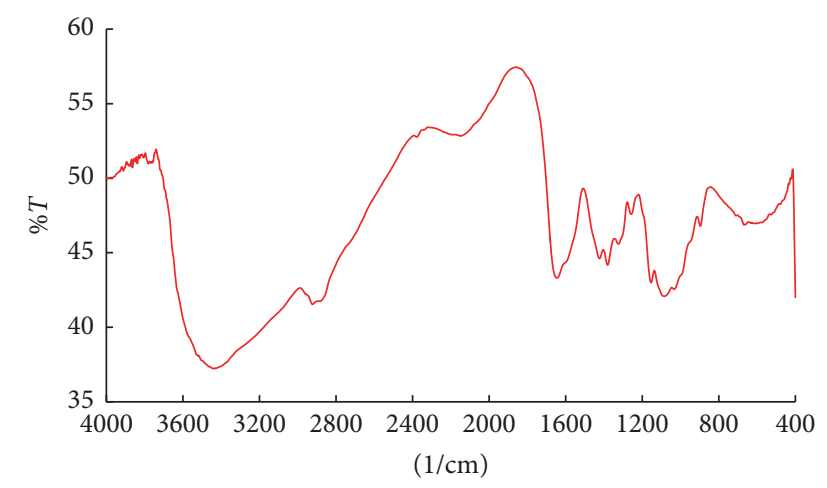

FIGURE 5: FTIR spectrum of chitosan.

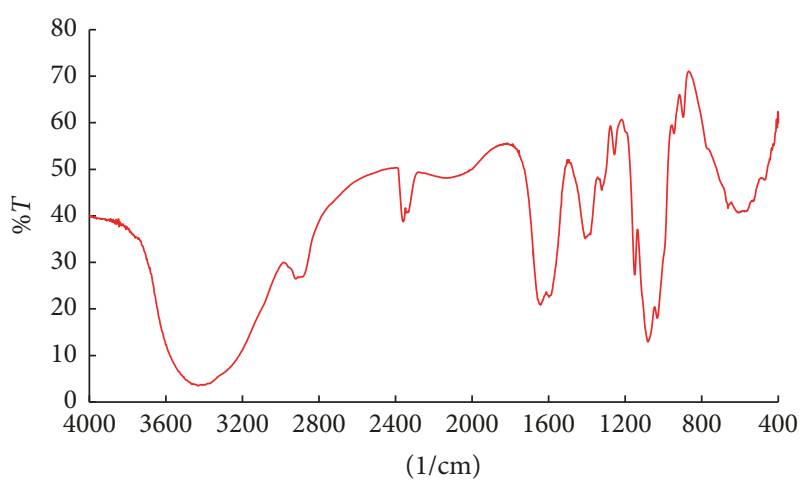

FIgURE 6: FTIR spectrum of CMC.

TABLE 2: Analysis of new functional groups of CMC-benzaldehyde using FTIR.

\begin{tabular}{lcc}
\hline $\begin{array}{l}\text { Functional } \\
\text { groups }\end{array}$ & $\begin{array}{c}\text { Wave numbers } \\
\text { according to Pretsch } \\
\text { et al. }\left(\mathrm{cm}^{-1}\right)\end{array}$ & $\begin{array}{c}\text { Wave numbers of } \\
\text { CMC-benzaldehyde from } \\
\text { the synthesis results }\left(\mathrm{cm}^{-1}\right)\end{array}$ \\
\hline $\mathrm{C}=\mathrm{N}$ & 1645 & 1641.31 \\
$\mathrm{C}=\mathrm{C}$ aromatic & 1600 & $1450-1600.81$ \\
\hline
\end{tabular}

substances. The higher concentration of these substances causes the corrosion rate of a metal to become faster.

In this study, $\mathrm{HCl} 1 \mathrm{M}$ is used as an oxidizing agent on steel. $\mathrm{HCl} 1 \mathrm{M}$ acts as an acid medium causing corrosion of steel, so that the corrosion rate can become faster in a relatively short time. Reactions that occur in this study can be described as follows:

$$
\mathrm{Fe}_{(\mathrm{s})}+2 \mathrm{HCl}_{(\mathrm{aq})} \longrightarrow \mathrm{FeCl}_{2(\mathrm{aq})}+\mathrm{H}_{2(\mathrm{~g})}
$$

The redox reaction consists of two half-cell reactions. These reactions are

$$
\begin{array}{cccc}
\text { Anode: } & \mathrm{Fe} & \longrightarrow & \mathrm{Fe}^{2+}+2 \mathrm{e} \\
\text { Cathode: } & 2 \mathrm{H}^{+}+2 \mathrm{e} & \longrightarrow & \mathrm{H}_{2} \\
\hline \mathrm{Fe}+2 \mathrm{H}^{+} & \longrightarrow & \mathrm{Fe}^{2+}+\mathrm{H}_{2}
\end{array}
$$

The half-cell reaction of the anode and cathode shows the exchange of electrons during the redox reaction process.

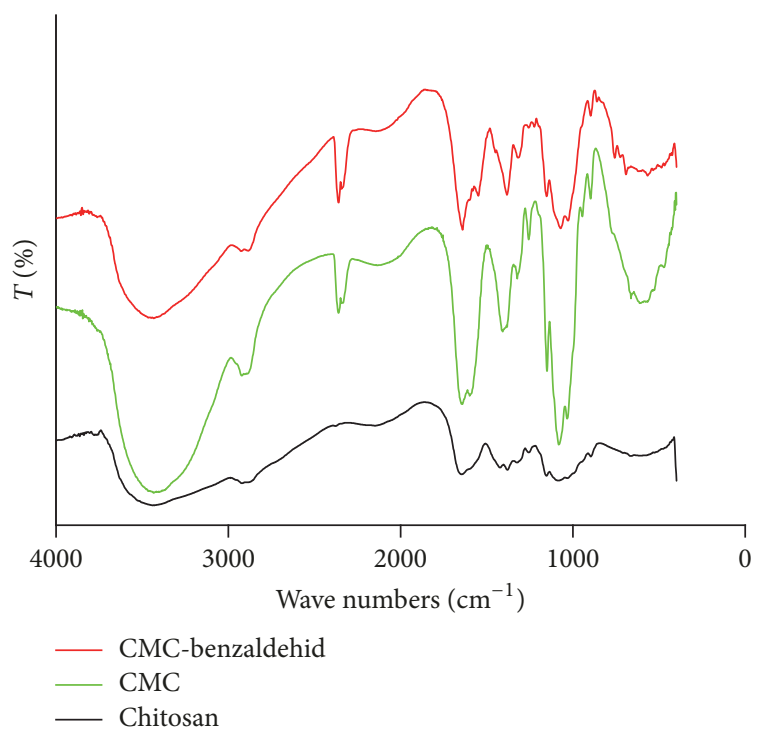

Figure 7: FTIR spectrum of chitosan, CMC, and CMCbenzaldehyde.

The corrosion mechanism of carbon steel without CMCbenzaldehyde inhibitors provides an opportunity of $\mathrm{H}^{+}$from the acid to be captured directly by the electrons that present in the steel so that the corrosion rate becomes fast. Steel without CMC-benzaldehyde inhibitors was used as a negative control in this study. Illustration of corrosion mechanisms on steel without CMC-benzaldehyde inhibitors can be seen in Figure 8(a).

The corrosion mechanism of steel with CMCbenzaldehyde inhibitors gives the chance of $\mathrm{H}^{+}$from the acid to be captured by the electrons present in the steel becoming smaller due to the less direct contact that occurs with the addition of CMC-benzaldehyde. Thus, the corrosion rate that occurs becomes slower when compared to the corrosion rate without the addition of CMC-benzaldehyde. Addition of CMC-benzaldehyde cannot cover all parts of steel. This is because CMC-benzaldehyde is a polymer that has an amorphous structure so that the coating on the steel still provides pores that allow the occurrence of contact with $\mathrm{H}^{+}$. Illustration of corrosion mechanisms on steel with CMC-benzaldehyde inhibitors can be seen in Figure 8(b).

Starch is added to CMC-benzaldehyde in order to cover the pores that are still not covered completely. It aims to reduce the contact between electrons on steel with $\mathrm{H}^{+}$. Illustration of corrosion mechanisms on steel with CMCbenzaldehyde inhibitors and starch can be seen in Figure 8(c).

\subsection{Effect of Addition of CMC-Benzaldehyde on Corrosion} Rate. Addition of CMC-benzaldehyde to steel is done by dripping and coating methods and the corrosion rate of the steel is carried out by potentiostatic polarization method. In this study, used variations in concentration on the addition of CMC-benzaldehyde are 1, 3, 5, and $7 \mathrm{~g}$ for $60 \mathrm{~mL}$ of solvent. In addition, in this study some treatments were added to starch of $0.1 \mathrm{~g} / \mathrm{mL}$ in CMC-benzaldehyde and some treatments were 


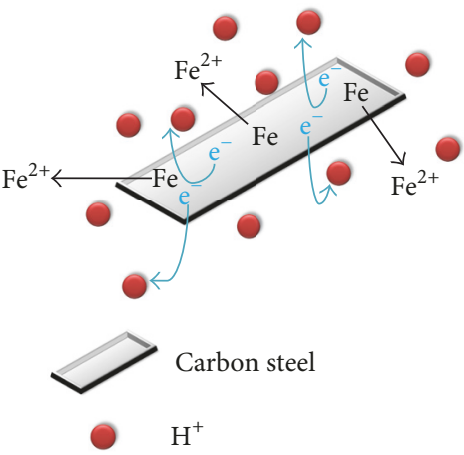

(a)

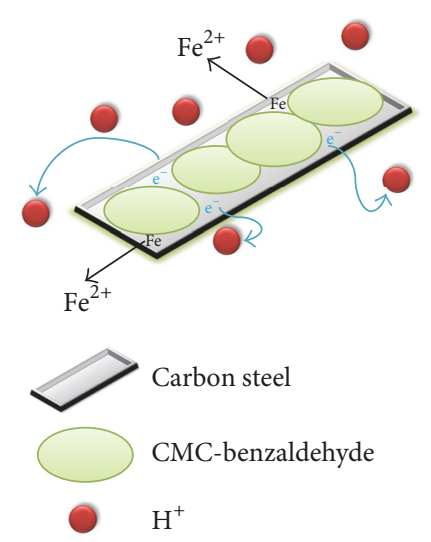

(b)

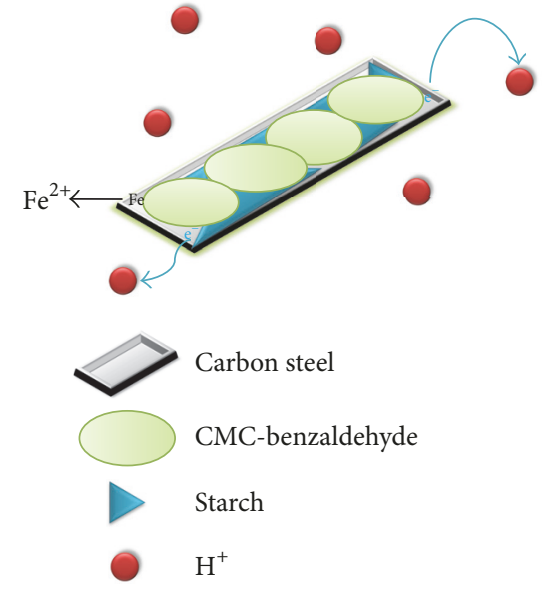

(c)

FIGURE 8: Hypothesis of corrosion mechanisms for the following: (a) without the addition of CMC-benzaldehyde inhibitors, (b) with the addition of CMC-benzaldehyde inhibitors, and (c) with the addition of CMC-benzaldehyde and starch inhibitors.

not added to starch. Addition of starch aims to reduce pores that are still not covered with CMC-benzaldehyde inhibitor, so optimal results are expected.

The negative control performed on steel without the addition of CMC-benzaldehyde showed that the corrosive rate caused by $\mathrm{HCl} 1 \mathrm{M}$ as corrosive medium was $5.89 \mathrm{~mm} /$ year with a corrosive current of $506.89 \mu \mathrm{A} / \mathrm{cm}^{2}$.

Dripping with CMC-benzaldehyde showed good results, where the corrosion rate and corrosion current decrease with the concentration of CMC-benzaldehyde that has been given. It also shows that the addition of CMC-benzaldehyde can cause the corrosion rate to be slower than without the addition of CMC-benzaldehyde.

Dripping with CMC-benzaldehyde and starch showed better results than dripping without the addition of starch. In dripping with CMC-benzaldehyde and starch, corrosion rates and corrosion currents decreased dramatically with increasing concentrations of CMC-benzaldehyde and starch that has been given.

And coating with CMC-benzaldehyde also showed decreasing corrosion rate and corrosion current along with increasing concentration of CMC-benzaldehyde that has been given.

Coating with CMC-benzaldehyde and starch also showed a decrease in corrosion rate and corrosion current along with the added concentration of CMC-benzaldehyde that has been given. In coating with CMC-benzaldehyde with a concentration of $7 \mathrm{~g}$ for $60 \mathrm{~mL}$ of solvent gives very low corrosion rate and corrosion current value compared to other treatments (dripping with CMC-benzaldehyde, dripping with CMC-benzaldehyde and starch, and coating with CMCbenzaldehyde). The values of corrosion rate and corrosion current are $0.0119 \mathrm{~mm} /$ year and $1.0203 \mu \mathrm{A} / \mathrm{cm}^{2}$, respectively. The effect of concentration of CMC-benzaldehyde with and without the addition of starch on the dripping and coating methods to the corrosion current and corrosion rate can be seen in Table 3.
3.5. Surface Morphology of Steel. In this study to determine the type of corrosion that occurs on steel is done using Scanning Electron Microscope (SEM). The morphology of the steel surface as a result of corrosion can be seen clearly when compared with seeing with the naked eye. Based on the SEM results, it can be seen that steel surfaces that have been added using CMC-benzaldehyde with and without starch after potentiostatic polarization testing have resulted in carbon steel having pitting corrosion. The analysis results of surface morphology using SEM for steel after potentiostatic polarization testing can be seen in Figure 9.

3.6. Inhibition Efficiency of CMC-Benzaldehyde against Corrosion Rate. Based on the calculated data of inhibition efficiency, the highest efficiency value to inhibit the corrosion rate is shown by coating method with CMC-benzaldehyde concentration of $7 \mathrm{~g} / 60 \mathrm{~mL}$ of solvent and starch of $0.1 \mathrm{~g} / \mathrm{mL}$ is $99.8 \%$. This indicates that CMC-benzaldehyde is able to inhibit corrosion rate of $99.8 \%$ and there is corrosion rate of $0.2 \%$ which can still occur in the steel that has been given treatment by adding CMC-benzaldehyde and starch. Inhibition efficiency from the results of research that has been done by dripping and coating methods using CMCbenzaldehyde with and without starch can be seen in Table 3 .

In the research that has been done by Erna et al. [12], the efficiency of corrosion inhibition of CMC for steels in water gives optimum results at $\mathrm{pH} 5$ and $\mathrm{CMC}$ concentration of $1 \mathrm{ppm}$ is $77 \%$. While in this study the use of CMCbenzaldehyde gives optimum results at concentration of $7 \mathrm{~g} / 60 \mathrm{~mL}$ of solvent and the addition of starch as much as $0.1 \mathrm{~g} / \mathrm{mL}$ in $\mathrm{HCl} 1 \mathrm{M}$ with $\mathrm{pH} 2.53$ is $99.8 \%$.

In addition, based on research that has been done by Finsgar and Jackson [13], the efficiency of CMC-benzaldehyde can also be compared with the use of other corrosion inhibitors in the oil and gas industry, as the use of $\mathrm{N}, \mathrm{N}^{\prime}$-ortho-phenylen acetyle acetone imine with concentrations of $50-400 \mathrm{mg} / \mathrm{L}$ in $\mathrm{HCl} 1 \mathrm{M}$ gives inhibitory efficiency of $24.9 \%-82.6 \%$. However, 
TABLE 3: The effect of concentration of CMC-benzaldehyde with and without the addition of starch on the dripping and coating methods to the corrosion current, corrosion rate, and inhibition efficiency.

\begin{tabular}{lcccc}
\hline Treatment & $\begin{array}{c}\text { Concentration } \\
(\mathrm{g} / 60 \mathrm{~mL} \text { of solvent })\end{array}$ & $\begin{array}{c}\text { Corrosion current } \\
\left(\mu \mathrm{A} / \mathrm{cm}^{2}\right)\end{array}$ & $\begin{array}{c}\text { Corrosion rate } \\
(\mathrm{mm} / \text { year })\end{array}$ & $\begin{array}{c}\text { Efficiency of inhibitor } \\
(\%)\end{array}$ \\
\hline Negative control & - & 506.89 & 5.8900 & - \\
\hline \multirow{2}{*}{ Dripping with } & 1 & 234.97 & 2.7303 & 1.8346 \\
CMC-benzaldehyde & 3 & 157.88 & 1.6525 & 71.94 \\
& 5 & 142.21 & 1.5237 & 74.13 \\
\hline Dripping with & 7 & 131.13 & 4.7008 & 20.19 \\
CMC-benzaldehyde and & 1 & 404.55 & 2.4360 & 58.64 \\
starch & 3 & 209.64 & 0.0576 & 99.02 \\
& 5 & 4.9576 & 0.0260 & 99.56 \\
\hline Coating with & 7 & 2.2381 & 4.5141 & 23.36 \\
CMC-benzaldehyde & 1 & 388.48 & 4.2437 & 27.95 \\
& 3 & 365.21 & 0.9261 & 84.28 \\
Coating with & 5 & 79.701 & 0.1704 & 97.11 \\
CMC-benzaldehyde and & 7 & 14.661 & 4.1080 & 30.25 \\
starch & 1 & 353.53 & 3.4710 & 41.07 \\
& 3 & 298.71 & 0.0295 & 9.0119 \\
\hline
\end{tabular}

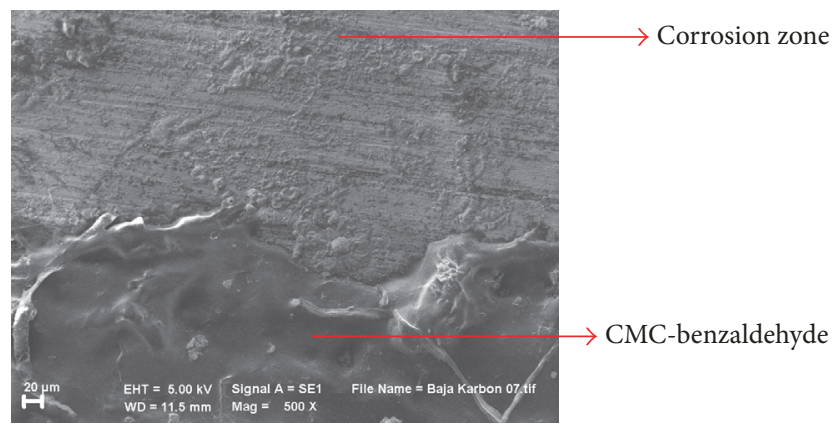

(a)

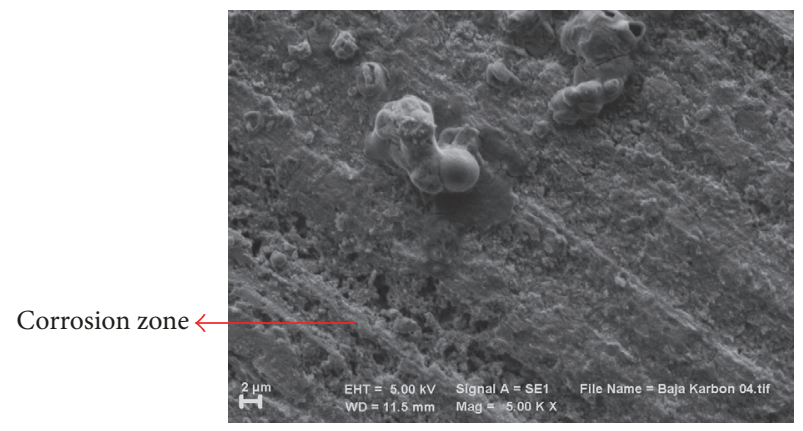

(b)

FIGURE 9: The analysis results of surface morphology using SEM for steel surfaces that have been added using (a) CMC-benzaldehyde with starch and (b) CMC-benzaldehyde without starch after potentiostatic polarization (coating method, concentration of $7 \mathrm{~g} / 60 \mathrm{~mL}$ ).

in this study the efficiency of CMC-benzaldehyde in the steels with concentrations of $1 \mathrm{~g} / 60 \mathrm{~mL}$ of solvent to $7 \mathrm{~g} / 60 \mathrm{~mL}$ of solvent by dripping and coating methods with and without starch in $\mathrm{HCl} 1 \mathrm{M}$ gives corrosion efficiency with range of $20.19 \%-99.8 \%$.

\section{Conclusion}

Based on the research that has been done and the data obtained, it can be concluded that CMC-benzaldehyde can be used as anticorrosion agent on steel. The effect of concentration on the corrosion rate of steel is that the higher concentration of CMC-benzaldehyde can make the corrosion rate on steel become slower. Conversely, the smaller CMCbenzaldehyde concentration that has been used makes the corrosion rate on steel become faster. The highest efficiency to inhibit corrosion rate on steel is $99.8 \%$ which can be obtained by coating method using CMC-benzaldehyde with concentration of $7 \mathrm{~g} / 60 \mathrm{~mL}$ of solvent and starch of $0.1 \mathrm{~g} / \mathrm{mL}$. The use of CMC-benzaldehyde inhibitors with concentrations of $1 \mathrm{~g} / 60 \mathrm{~mL}$ of solvent to $7 \mathrm{~g} / 60 \mathrm{~mL}$ of solvent gives corrosion efficiency with range of $20.19 \%-99.8 \%$.

\section{Disclosure}

The paper was represented as an abstract which is part of undergraduate thesis and can be seen in the link: http:// repository.unair.ac.id/28231/1/gdlhub-gdl-s1-2014-anggaraleo-37493-5.-abstr-k.pdf.

\section{Conflicts of Interest}

The authors declare no competing financial interests. 


\section{References}

[1] A. Gunaatmaja, Pengaruh Waktu Perendaman terhadap Laju Korosi pada Baja Karbon Rendah dengan Penambahan Ekstrak Ubi Ungu sebagai Inhibitor Organik di Lingkungan $\mathrm{NaCl} \mathrm{3,5 \% ,}$ Universitas Indonesia, Java, Indonesia, 2011.

[2] K. R. Trethewey and J. Chamberlain, Corrosion for Students of Science and Engineering, Longman Scientific \& Technical, New York, NY, USA, 1988.

[3] R. W. Revie and H. H. Uhlig, Corrosion and Corrosion Control: An Introduction to Corrosion Science and Engineering, John Wiley \& Sons, Hoboken, New Jersey, USA, 4th edition, 2008.

[4] F. R. de Abreu and S. P. Campana-Filho, "Characteristics and properties of carboxymethylchitosan," Carbohydrate Polymers, vol. 75, no. 2, pp. 214-221, 2009.

[5] X. Xue, L. Li, and J. He, "The performances of carboxymethyl chitosan in wash-off reactive dyeings," Carbohydrate Polymers, vol. 75, no. 2, pp. 203-207, 2009.

[6] F. S. de Souza and A. Spinelli, "Caffeic acid as a green corrosion inhibitor for mild steel," Corrosion Science, vol. 51, no. 3, pp. 642-649, 2009.

[7] M. Zheng, B. Han, Y. Yang, and W. Liu, "Synthesis, characterization and biological safety of O-carboxymethyl chitosan used to treat Sarcoma 180 tumor," Carbohydrate Polymers, vol. 86, no. 1, pp. 231-238, 2011.

[8] X.-G. Chen and H.-J. Park, "Chemical characteristics of $O$ carboxymethyl chitosans related to the preparation conditions," Carbohydrate Polymers, vol. 53, no. 4, pp. 355-359, 2003.

[9] T. F. Jiao, J. Zhou, L. Gao, Y. Y. Xing, and X. Li, "Synthesis and characterization of chitosan-based schiff base compounds with aromatic substituent groups," Iranian Polymer Journal, vol. 20, no. 2, pp. 123-136, 2011.

[10] W. D. Callister, Material Science and Engineering: An Introduction, Wiley, New York, NY, USA, 1985.

[11] E. Pretsch, Th. Clerc, J. Seibl, and W. Simon, Tables of Spectral Data for Structure Determination of Organic Compounds, Springer-Verlag Berlin Heidelberg, Berlin, Germany, 2nd edition, 1989.

[12] M. Erna, E. Emriadi, A. Alif, S. Arief, and M. J. Noordin, "Sintesis dan aplikasi karboksimetil kitosan sebagai inhibitor korosi pada baja karbon dalam air," Jurnal Natur Indonesia, vol. 12, no. 1, pp. 87-92, 2009.

[13] M. Finsgar and J. Jackson, "Application of corrosion inhibitors for steels in acidic media for the oil and gas industry: A review," Corrosion Science, vol. 86, pp. 17-41, 2014. 


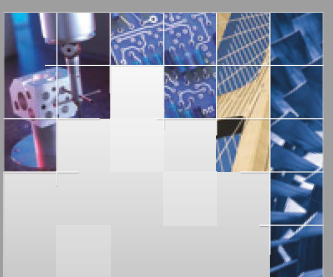

\section{Enfincering}
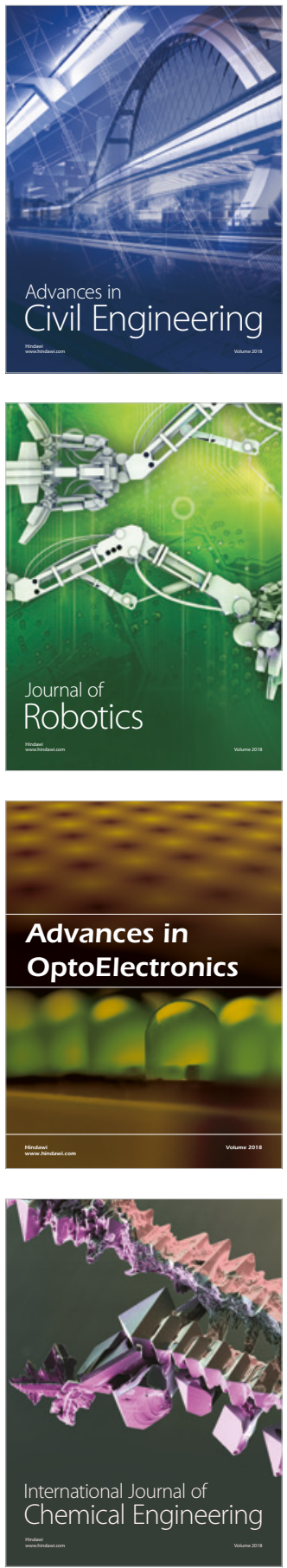

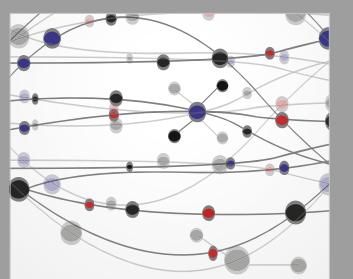

\section{Rotating \\ Machinery}

The Scientific World Journal

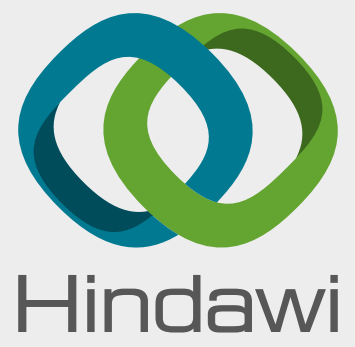

Submit your manuscripts at

www.hindawi.com
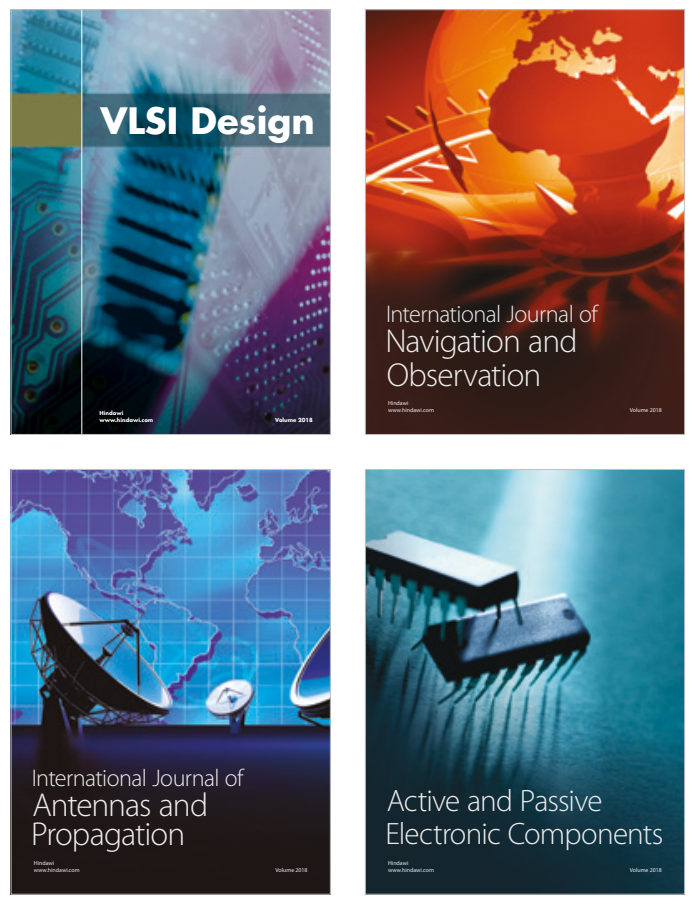
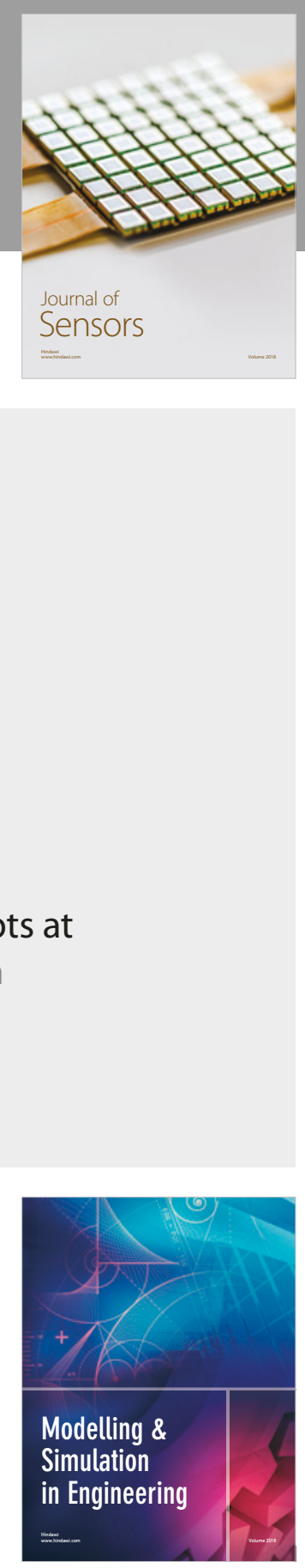

\section{Advances \\ Multimedia}
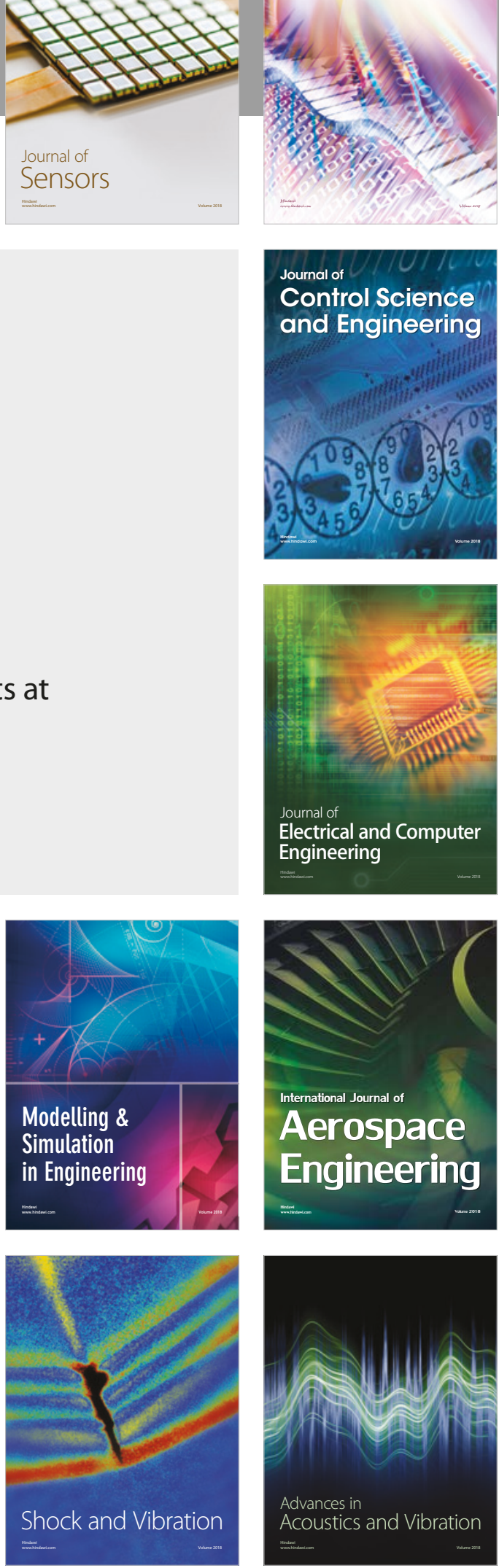